\title{
Work intensity in sacroiliac joint fusion and lumbar microdiscectomy
}

\author{
Clay Frank' \\ Dimitriy Kondrashov ${ }^{2}$ \\ S Craig Meyer ${ }^{3}$ \\ Gary Dix ${ }^{4}$ \\ Morgan Lorio 5 \\ Don Kovalsky ${ }^{6}$ \\ Daniel Cher ${ }^{7}$ \\ 'Integrated Spine Care, Wawautosa, \\ WI, ${ }^{2}$ St Mary's Spine Center, San \\ Francisco, CA, ${ }^{3}$ Columbia Orthopedic \\ Group, Columbia, MO, ${ }^{4}$ Maryland \\ Brain Spine and Pain, Annapolis, MD, \\ ${ }^{5}$ Neurospine Solutions, Bristol, TN, \\ ${ }^{6}$ Orthopaedic Center of Southern \\ Illinois, Mt Vernon, IL, ${ }^{7} \mathrm{SI}-\mathrm{BONE}$, Inc., \\ San Jose, CA, USA
}

Correspondence: Daniel Cher SI-BONE, Inc., 3055 Olin Avenue, Suite 2200, San Jose, CA, USA 95128 Email dcher@si-bone.com
This article was published in the following Dove Press journal:

ClinicoEconomics and Outcomes Research

26 July 2016

Number of times this article has been viewed

Background: The evidence base supporting minimally invasive sacroiliac (SI) joint fusion (SIJF) surgery is increasing. The work relative value units (RVUs) associated with minimally invasive SIJF are seemingly low. To date, only one published study describes the relative work intensity associated with minimally invasive SIJF. No study has compared work intensity vs other commonly performed spine surgery procedures.

Methods: Charts of 192 patients at five sites who underwent either minimally invasive SIJF (American Medical Association [AMA] CPT® code 27279) or lumbar microdiscectomy (AMA CPT® code 63030) were reviewed. Abstracted were preoperative times associated with diagnosis and patient care, intraoperative parameters including operating room (OR) in/out times and procedure start/stop times, and postoperative care requirements. Additionally, using a visual analog scale, surgeons estimated the intensity of intraoperative care, including mental, temporal, and physical demands and effort and frustration. Work was defined as operative time multiplied by task intensity.

Results: Patients who underwent minimally invasive SIJF were more likely female. Mean procedure times were lower in SIJF by about 27.8 minutes $(P<0.0001)$ and mean total OR times were lower by 27.9 minutes $(P<0.0001)$, but there was substantial overlap across procedures. Mean preservice and post-service total labor times were longer in minimally invasive SIJF (preservice times longer by 63.5 minutes $[P<0.0001]$ and post-service labor times longer by 20.2 minutes $[P<0.0001])$. The number of postoperative visits was higher in minimally invasive SIJF. Mean total service time (preoperative + OR time + postoperative) was higher in the minimally invasive SIJF group ( 261.5 vs 211.9 minutes, $P<0.0001)$. Intraoperative intensity levels were higher for mental, physical, effort, and frustration domains $(P<0.0001$ each). After taking into account intensity, intraoperative workloads showed substantial overlap.

Conclusion: Compared to a commonly performed lumbar spine surgical procedure, lumbar microdiscectomy, that currently has a higher work RVU, preoperative, intraoperative, and postoperative workload for minimally invasive SIJF is higher. The work RVU for minimally invasive SIJF should be adjusted upward as the relative amount of work is comparable.

Keywords: sacroiliac joint fusion, work intensity, spine surgery, reimbursement

\section{Introduction}

Low back pain is one of the most common health conditions accounting for loss of health quality globally. ${ }^{1}$ The incidence of lumbar spine surgeries has risen remarkably in the past two decades, ${ }^{2}$ but success rates after such surgeries continue to be modest at best.

Although the sacroiliac (SI) joint has been recognized as a pain generator since the 1800s, and despite the fact that the first SI joint fusion (SIJF) was performed in 
the early $1900 \mathrm{~s}^{3}$ prior to the first lumbar discectomy (1934), ${ }^{4}$ the SI joint remains a relatively unrecognized source of pain. Several cross-sectional studies have shown that the SI joint may cause $15 \%-30 \%$ of all chronic lower back pain. ${ }^{5-8}$ The SIJ is even more commonly (up to $40 \%{ }^{9,10}$ ) suspected as a source of low back pain in patients with prior lumbar fusion, either because fixation of the lumbar spine increases forces on the adjacent SI joint or because the SI joint was not initially diagnosed as the pain generator.

Currently available nonsurgical treatment options for SIJ dysfunction include physical therapy, ${ }^{11}$ prolotherapy, SI belt, SIJ steroid injections, ${ }^{12,13}$ and radiofrequency ablation of the lateral branches of the sacral nerve roots. ${ }^{14,15}$ No high-quality evidence is available to support the long-term effectiveness of these treatments. Open SIJF, though the subject of several retrospective case series, ${ }^{16-22}$ is now no longer commonly performed for chronic pain and minimally invasive methods are preferred. ${ }^{23}$ Of the several devices currently available for minimally invasive SIJF, clinical evidence is only available for triangular titanium implants placed during a lateral, transiliac, transarticular approach. Clinical evidence includes a prospective multicenter randomized trial, ${ }^{24}$ a prospective multicenter single-arm study, ${ }^{25}$ several single-center case series, ${ }^{26-32}$ a combined multicenter analysis, ${ }^{33}$ and a systematic review. ${ }^{34}$ Published data, especially the randomized trial, show that minimally invasive SIJF provides superior pain, disability, and quality of life outcomes compared to non-surgical management in appropriately selected patients.

The relative value unit (RVU) scale is a payment mechanism developed by Harvard physicians in the late $1980 \mathrm{~s}^{35}$ that the Centers for Medicare and Medicaid Services uses to determine US physician reimbursement based on relative work values. Since 1991, RVUs have been developed by the American Medical Association-based Relative Value Scale Update Committee (RUC) in a proprietary and often criticized process. ${ }^{36,37}$ There are three components that impact the overall value of an RVU: 1) the physician's individual workload for the health care service, 2) the physician's outlays for non-time-based practice resources (eg, office space and staff and supplies), and 3) professional liability insurance. Regarding service workload, RVUs are based on preoperative, intraoperative, and postoperative time considerations and a poorly defined "work intensity". ${ }^{38}$

Recently, the AMA CPT ${ }^{\circledR}$ Editorial Panel determined that the existing code for open SIJF was not applicable to minimally invasive SIJF and it subsequently assigned a temporary Category III tracking (T) code until adequate data regarding safety and effectiveness of minimally invasive
SIJF were published. The common consequence of a $\mathrm{T}$ code is near-universal denial of coverage for the procedure by both Medicare and private insurance companies. Based on increasing published clinical literature supporting safety and effectiveness of minimally invasive SIJF, the AMA CPT ${ }^{\circledR}$ Editorial Panel created a Category I code (CPT ${ }^{\circledR}$ 27279), effective from January 1, 2015. The new Category I code was then sent to the RUC for valuation. Using a crosswalk methodology, the RUC recommended a work RVU of 9.03, equivalent to that of percutaneous endoscopic discectomy $\left(\mathrm{CPT}^{\circledR}\right.$ 62287), a procedure that most spine surgeons do not perform. Like most surgical procedures, SIJF involves blunt dissection at the start and layered skin closure at the end. Moreover, the procedure involves placement of typically three permanent implants. A typical percutaneous pain management procedure lacks these steps. Additionally, a significant percentage of surgeons utilize neurological monitoring for minimally invasive SIJF to minimize the potential for irritating either L5 or S1 nerve roots by the fusion implants. The neuromonitoring setup is frequently performed by the surgeon in the operating room (OR) and, in the vast majority of the cases, is non-reimbursable by the insurance companies. These factors distinguish minimally SIJF from lumbar microdiscectomy (LMD).

Garber et $\mathrm{al}^{39}$ examined the work effort involved in minimally invasive SIJF and assessed this work effort against the comparator of $\mathrm{LMD}\left(\mathrm{CPT}^{\circledR}\right.$ code 63030 ; valued at 13.18 work RVUs), a procedure commonly performed by spine surgeons. They found the work RVU for CPT ${ }^{\circledR} 27279$ to be insufficient ${ }^{39}$ and not reflective of the degree of work involved due to the average intraoperative time (119 minutes for LMD compared to 112 minutes for SIJF) and postoperative time (patients who underwent minimally invasive SIJF were kept overnight in the hospital while LMD patients were typically sent home). ${ }^{39}$ The authors' findings suggest that at a minimum, the physician work for minimally invasive SIJF should be at least the same as LMD (13.18 RVUs) and most likely greater than LMD.

In this study, we extend the findings of this study by collecting and comparing pre- and postoperative service times and intraoperative times and work intensity for the same two procedures.

\section{Methods}

This study focuses on two of the three procedures listed in Table 1. Minimally invasive SIJF is associated with a current work RVU of 9.03, the same value as of automated percutaneous and endoscopic discectomy (a procedure surgeons typically do not perform). Following the methods of Garber 
Table I Spine surgical procedures and associated coding and current RVU

\begin{tabular}{lll}
\hline Procedures & CPT code & 2016 work RVUs* \\
\hline Posterior lumbar microdiscectomy & 63030 & 13.18 \\
Percutaneous discectomy & 62287 & 9.03 \\
Minimally invasive sacroiliac joint & 27279 & 9.03 \\
fusion & & \\
\hline
\end{tabular}

Notes: *Data from https://www.cms.gov/Medicare/Medicare-Fee-for-Service-Payment/ PhysicianFeeSched/PFS-Federal-Regulation-Notices-Items/CMS-163I-FC.html. ${ }^{54}$

Abbreviations: CPT, current procedural technology; RVU, relative value unit.

et $\mathrm{al},{ }^{39}$ our study focused on patients who underwent either minimally invasive SIJF or a commonly performed surgical procedure of similar OR duration, namely posterior lumbar laminotomy/LMD. Minimally invasive SIJF is used to address chronic pain associated with SI joint degeneration or disruption. LMD is used in patients with pain associated with a herniated nucleus pulposus (disc).

Physician participants identified the most recent patients who underwent minimally invasive SIJF or LMD (with a goal of 20 patients for each procedure for each physician) using clinic records or surgical facility databases. Abstracted from the chart were basic demographics and characteristics of the surgical procedure. In addition, OR "in" and "out" times were collected, as well as procedure start/stop "skin-to-skin" times. At one side, anesthesia start/stop times were used in place of OR in/out times. Preoperative labor was retrospectively assessed through chart review, taking into account minutes required for physical exam, educational and treatment option discussions with the patient, surgical consent, interpretation of diagnostic tests, completion of forms to order diagnostic tests, non-surgical treatments, such as injections and/ or physical therapy and surgery, and additional time spent on the phone or writing letters. Postoperative service was calculated during the 90-day global period by summing the number of visits coded using either generic visit CPT codes or postoperative codes and adding time spent on the phone, or ordering and interpreting postoperative treatments/tests. Postsurgical complications were also assessed.

Next, work intensity was measured using selected questions from the NASA task load index (TLX) ${ }^{40}$ a measurement tool based on visual analog scale ratings that has been used in multiple studies of health care task intensity. The six TLX rating domains used are shown in Table 2. Each task was rated by the surgeon using a visual analog scale. Workload was defined as operative time multiplied by task intensity.

Skin-to-skin time and OR in-out time were compared using a mixed effects model with physician as a random effect and surgery type, age, sex, and body mass index
Table 2 NASA TLX rating system

\begin{tabular}{|c|c|c|}
\hline Components & Questions & Rating scale \\
\hline Mental demand & $\begin{array}{l}\text { How mentally demanding was } \\
\text { the task? }\end{array}$ & Very low-very high \\
\hline Physical demand & $\begin{array}{l}\text { How physically demanding was } \\
\text { the task? }\end{array}$ & Very low-very high \\
\hline Temporal demand & $\begin{array}{l}\text { How hurried or rushed was the } \\
\text { pace of the task? }\end{array}$ & Very low-very high \\
\hline Performance & $\begin{array}{l}\text { How successful were you in } \\
\text { accomplishing what you were } \\
\text { asked to do? }\end{array}$ & Perfect-failure \\
\hline Effort & $\begin{array}{l}\text { How hard did you have to } \\
\text { work to accomplish your level } \\
\text { of performance? }\end{array}$ & Very low-very high \\
\hline Frustration & $\begin{array}{l}\text { How insecure, discouraged, } \\
\text { irritated, stressed, and annoyed } \\
\text { were you? }\end{array}$ & Very low-very high \\
\hline
\end{tabular}

Abbreviation: NASA, National Aeronautics and Space Administration; TLX, task load index.

(BMI) as fixed effects. Nominal variables were compared using chi-squared tests. Ordinal variables (eg, length of stay) were compared using proportional odds logistic regression. The number of postoperative visits was compared using proportional odds logistic regression. The goal of analysis was to compare total service times, intraoperative times, workload, and postoperative visits across the two treatments (minimally invasive SIJF and LMD). All statistical analyses were performed using R. ${ }^{41}$

The study was approved by a central Schulman IRB, with patient consent waived as the study involved no patient contact and no protected health information was collected.

\section{Results}

Five surgeons participated in the study. Study patients included 96 patients who underwent minimally invasive SIJF and 96 patients who underwent LMD. Compared to LMD, patients who underwent SIJF were more likely women $(65.6 \%$ vs $39.6 \%, P=0.0005$; Table 3 ). (SI joint dysfunction is known to have a female predominance.) The proportion who were smokers was similar $(P=0.0915)$. Mean age was slightly higher in the SIJF group (by about 5.78 years, $P=0.0044$ ) and BMI was similar.

Preoperative service times were higher in the minimally invasive SIJF group (mean 116.6 vs 58.5 minutes; Figure 1, top left). The adjusted mean difference was 63.5 minutes $(P<0.0001)$. Mean skin-to-skin procedure times were lower for minimally invasive SIJF compared to LMD (49.9 minutes vs 77.5 minutes; Figure 1, top right). Controlling for physician, age, sex, and BMI, the difference in mean times was 27.8 minutes $(95 \%$ confidence interval $[\mathrm{CI}] 22-33.5, P<0.0001)$. Mean OR in/out times were also lower for minimally invasive 

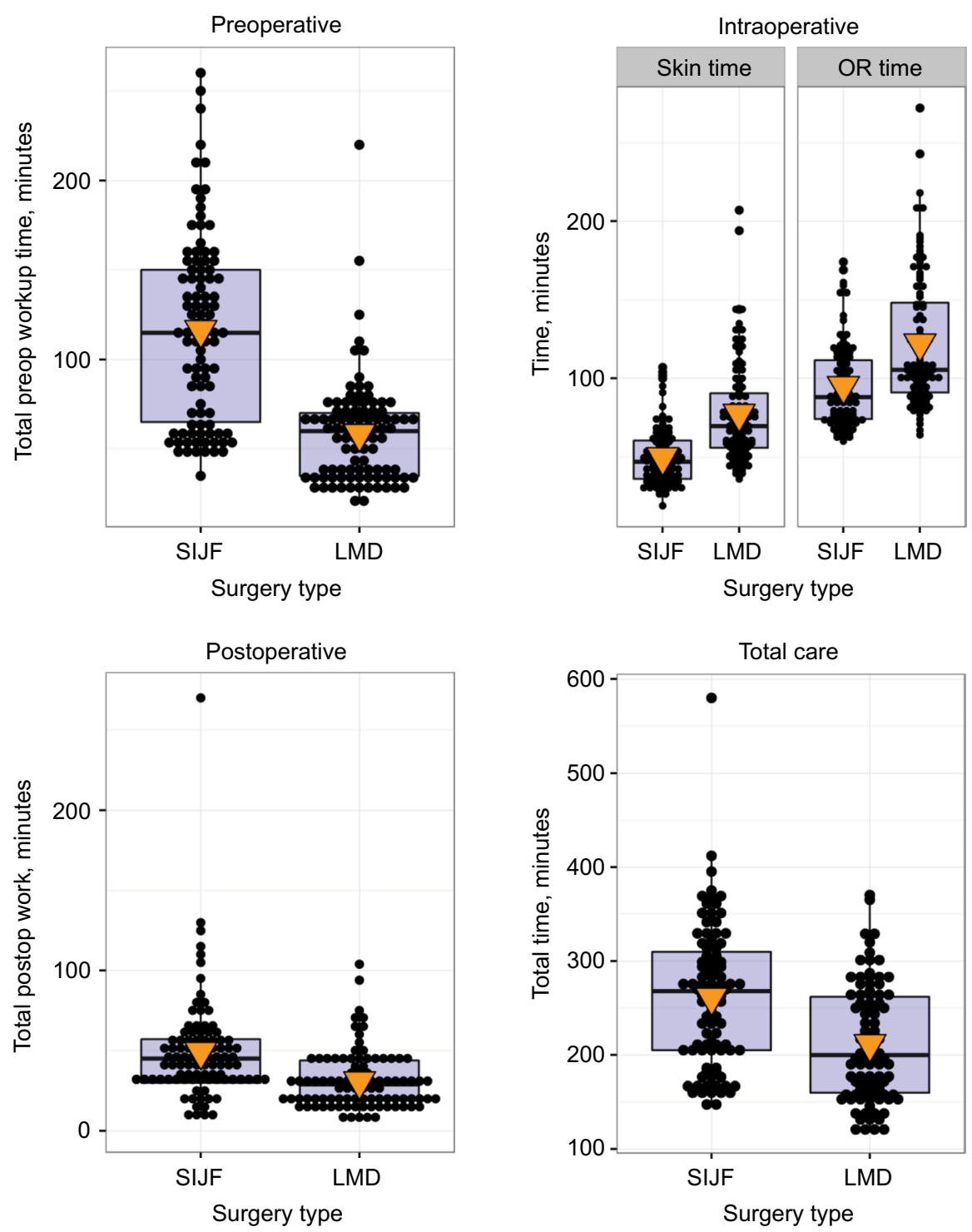

Figure I Preoperative care time (top left), intraoperative skin-to-skin and OR times (top right), postoperative care time (bottom left), and total care time (bottom right). Notes: Dots show individual values and triangles show mean values. Standard box-plot parameters are shown (bar $=$ median, box limits $=$ interquartile ranges). All distributions are significantly higher for SIJF vs LMD $(P<0.000 \mathrm{I})$.

Abbreviations: OR, operating room; SIJF, sacroiliac joint fusion; LMD, lumbar microdiscectomy; postop, postoperative.

Table 3 Baseline characteristics of study patients

\begin{tabular}{llll}
\hline & $\begin{array}{l}\text { SIJF } \\
(\mathbf{n = 9 6 )}\end{array}$ & $\begin{array}{l}\text { LMD } \\
(\mathbf{n = 9 6 )}\end{array}$ & P-value \\
\hline Age, mean (range) & $56.6(31-83)$ & $50.9(19-88)$ & 0.0044 \\
Female, N (\%) & $63(65.6)$ & $38(39.6)$ & 0.0005 \\
BMI, mean (range) & $29.9(18-49)$ & $30.0(16-51)$ & 0.8794 \\
Smoker, N (\%) & $15(15.6)$ & $26(27.1)$ & 0.0915 \\
\hline
\end{tabular}

Abbreviations: SIJF, sacroiliac joint fusion; LMD, lumbar microdiscectomy; BMI, body mass index.

SIJF (95.3 vs 122.4 minutes; Figure 1, top right). Controlling for BMI, the difference in mean OR times was 27.9 minutes (95\% CI 21.5-34.3, $P<0.0001)$. There was substantial overlap in operative time distributions, and the difference in skin and OR times varied substantially from one site to the next. Mean hospital length of stay was higher for minimally invasive SIJF compared to LMD ( 0.6 vs 0.2 days, $P<0.0001)$. The proportion of patients with procedure-related adverse events was $7.3 \%$ for minimally invasive SIJF and $7.3 \%$ for LMD. Postoperative service times were higher in the minimally invasive SIJF group (49.5 vs 31.0 minutes, $P<0.0001$; Figure 1 , bottom left). The number of postoperative visits within the 90-day global period was higher in minimally invasive SIJF (mean 2.5 vs 2.1, proportional odds logistic regression, $P=0.0113)$. Total care time, defined as preoperative labor + OR time + postoperative labor, was, on average, higher in the minimally invasive SIJF group compared to the LMD group (mean 261.5 vs 211.9 minutes; Figure 1, bottom right), representing a $23 \%$ increase $(P<0.0001)$. 
TLX intensity ratings were higher in the minimally invasive SIJF group for the mental, physical, effort and frustration domains (all $P<0.0001$ ), higher for the temporal domain $(P=0.0051)$, but similar for the performance subdomain $(P=0.7214)$. Workload, defined as OR time $\times$ intensity, was higher in the SIJF group for the frustration domain ( $P=0.0014)$, and similar for mental $(P=0.8063)$, performance ( $P=0.2361)$, and effort domains $(P=0.9173)$, but somewhat lower for physical $(P=0.0518)$ and temporal $(P=0.0034)$ domains (Figure 3 ). For workload measurements, both substantial overlap in distributions and variations in directionality across physicians for some domains were found.

\section{Discussion}

SIJF is a relatively new procedure with an increasing highquality evidence base. Most published studies have reported outcomes after use of triangular titanium implants. The current evidence base includes a landmark multicenter randomized controlled trial (INSITE, $\mathrm{n}=148$ ), ${ }^{24}$ which showed marked superiority of minimally invasive surgery vs non-surgical management, a second similar trial (iMIA, ${ }^{42}$ NCT01741025) conducted in Europe and showing consonant results, a prospective two-year study in the US, ${ }^{43}$ singlecenter case series, ${ }^{27-29,33,44,45}$ multicenter case series, ${ }^{46}$ and comparative studies vs open fusion. ${ }^{33,47,48}$ The procedure has demonstrated reasonable cost-effectiveness, ${ }^{49}$ and a cost model suggests that failure to consider the SI joint during workup of patients with chronic low back pain considering surgery may waste, on average, $\$ 3,000$ per patient over 2 years. ${ }^{50}$

Along with the rapidly growing evidence base, $\mathrm{CPT}^{\circledR}$ codes for the procedure have evolved over the past few years. The current work RVU for minimally invasive SIJF appeared low to study authors, motivating a comparison of intraoperative work intensity and pre- and postoperative labor times of this procedure vs LMD, a commonly performed spine surgery procedure with higher work RVUs. Given that the philosophy of developing work RVUs is to take into account both service time and work intensity, ${ }^{35}$ we believed that a careful analysis comparing the procedures would show that the current work RVU for minimally invasive SIJF was inadequate.

It was our prior hypothesis that pre- and postoperative service times would be higher for minimally invasive SIJF. Preoperative labor times were approximately 1 hour more for minimally invasive SIJF. This difference is probably explained by the complexity of workup for SI joint dysfunction compared to lumbar disc herniation. Workup for SI joint dysfunction involves performing specific physical examination maneuvers that are thought to be predictive of a positive SI joint block, ${ }^{51}$ a confirmatory diagnostic test (anesthetic SI joint block), the time of which was not included in this analysis, and a careful consideration of cross-sectional imaging, which is used primarily to rule out other conditions. This is done in addition to the conventional physical examination for both the lumbar spine and the hip joints. Had we included time required for SI joint block (often performed by a separate physician, typically a pain specialist or anesthesiologist), physician preservice times between the two procedures would have shown even larger differences. Substantial time was required for patient education, preoperative counseling, and other preoperative activities. In contrast, lumbar disc herniation is easily identified on physical examination and magnetic resonance imaging, and preoperative education requires less time. Taking into account the range of preoperative service times for a wide variety of procedures reported by Dunn et al, ${ }^{52}$ differences of 1 hour are very high. Postoperatively, service times were also higher for minimally invasive SIJF. This is not surprising in that minimally invasive SIJF involves placement of multiple permanent implants and LMD involves only resection of disc tissue compressing the nerve. Similarly, length of hospital stay was substantially longer in the minimally invasive SIJF group. When summed, total care time, defined as preoperative + intraoperative + postoperative time, was higher in the minimally invasive SIJF group by 50 minutes, or $23 \%$.

For intraoperative measures, we found substantial overlap in intraoperative skin-to-skin times and OR in-out times between the two procedures. Mean skin-to-skin times were about 27.8 minutes lower for minimally invasive SIJF and total OR times were lower by a similar duration (27.9 minutes). Skin-to-skin and OR times and time differences varied according to physician. The surgeons in our study are highly skilled in the SIJF procedure, having performed from $>80$ to $>210$ cases in the past 5 years. A less-experienced surgeon would likely take longer to perform SIJF and the differences in skin-to-skin and OR times could be smaller.

The RVU approach clearly indicates that workload should take into account both time and intensity. Intensity measures were higher for SIJF in the following domains: mental demand, physical demand, temporal pace, effort, and frustration. The higher intensity measures in SIJF resulted in smaller differences in workloads across procedures, which offset somewhat lower OR times (Figure 3). There was substantial overlap in workload distributions for most measures. Taken together, our findings (increased pre-, post- and total service time and increased intraoperative intensity) suggest that the current work RVU for minimally invasive SIJF is 
Mental

(How mentally demanding was the task?)

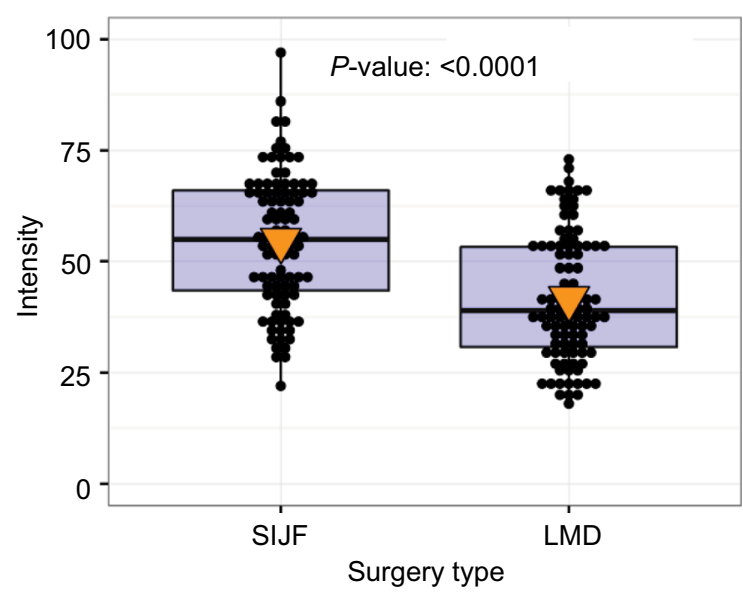

Temporal

(How hurried or rushed was the pace of the task?)

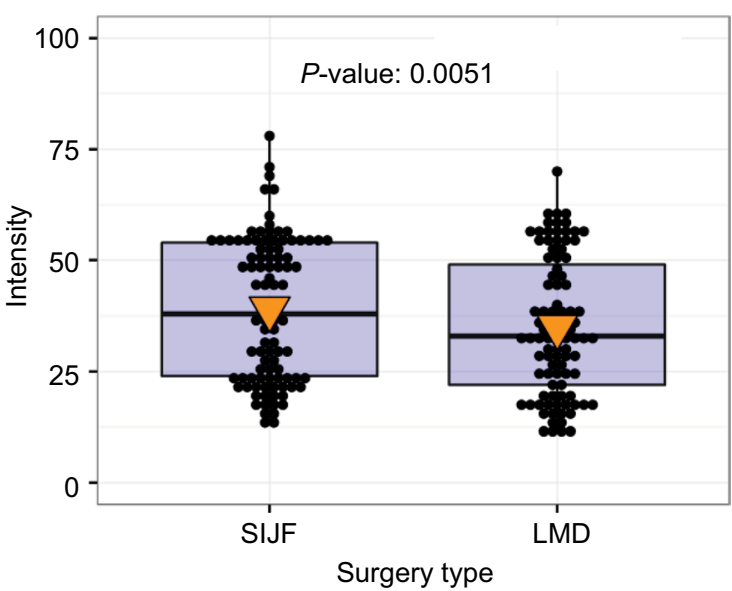

Effort

(How hard did you have to work to accomplish your level of performance?)

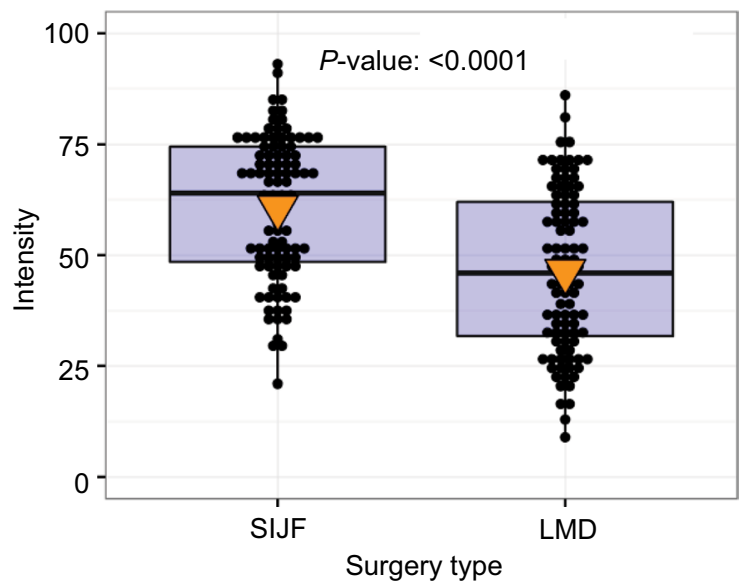

Physical

(How physically demanding was the task?)

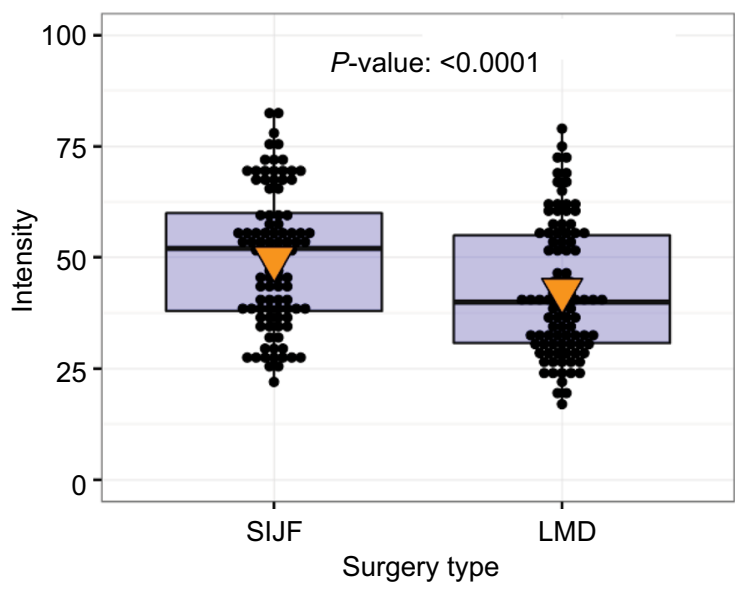

Performance

(How successful were you in accomplishing what you were asked to do?)

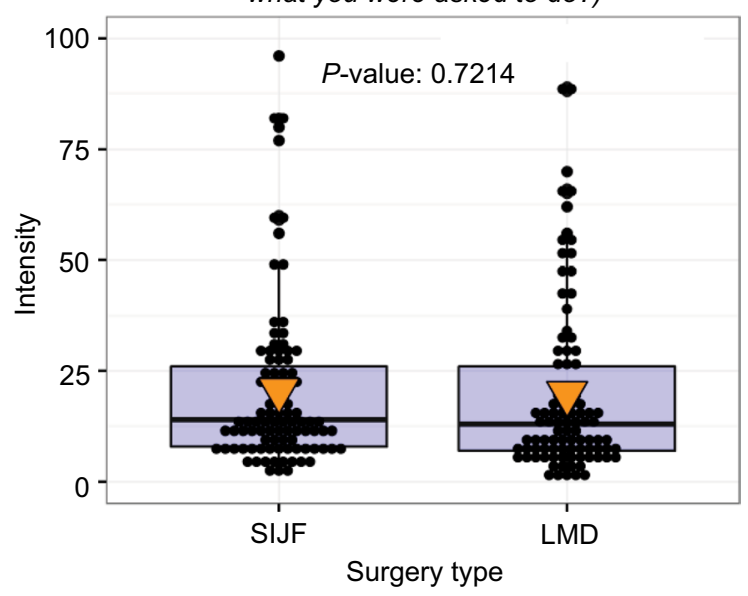

Frustration

(How insecure, discouraged, distressed did you feel?)

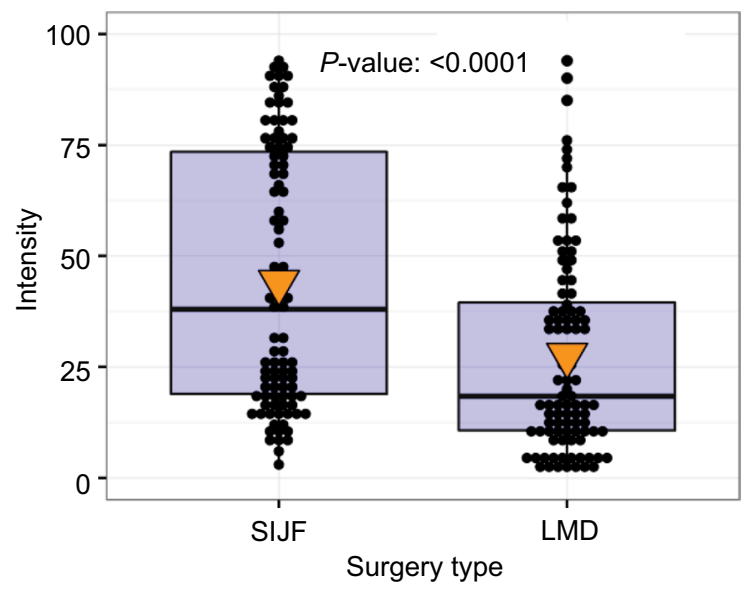

Figure 2 Intraoperative intensity by surgery type and subdomain.

Note: $y$-Axis is scaled as $0=$ "very low" to $100=$ "very high" for all domains except performance, which extends from $0=$ "perfect" to $100=$ "failure." Abbreviations: SIJF, sacroiliac joint fusion; LMD, lumbar microdiscectomy. 
Workload: Mental

(How mentally demanding was the task?)

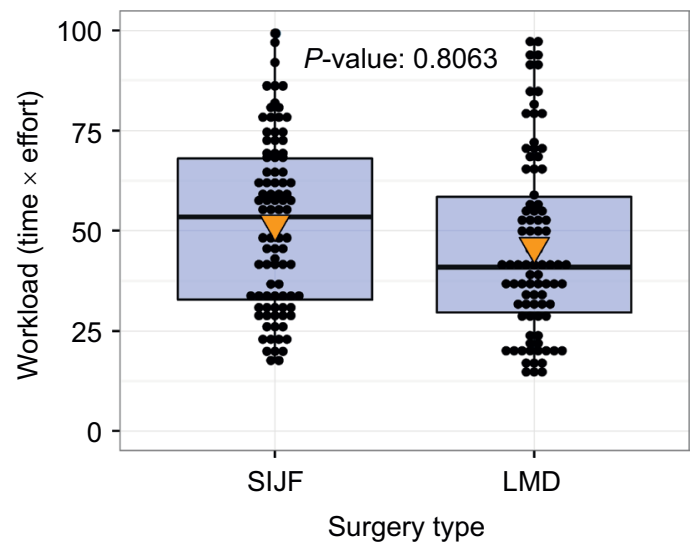

Workload: temporal

(How hurried or rushed was the pace of the task?)

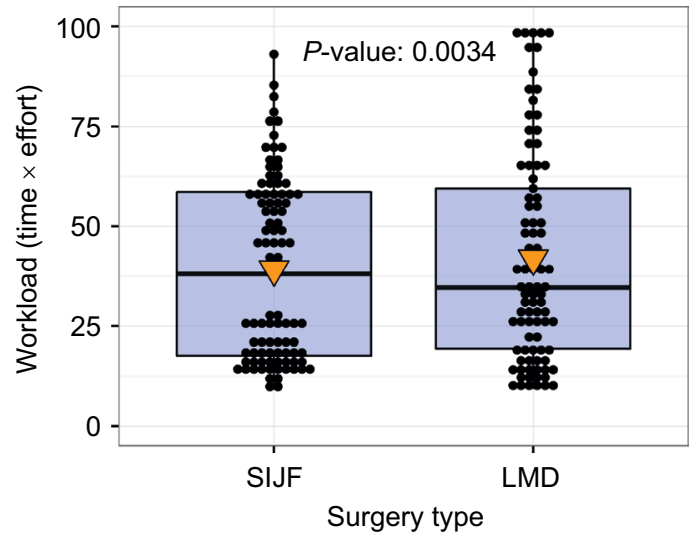

Workload: effort

(How hard did you have to work to accomplish your level of performance?)

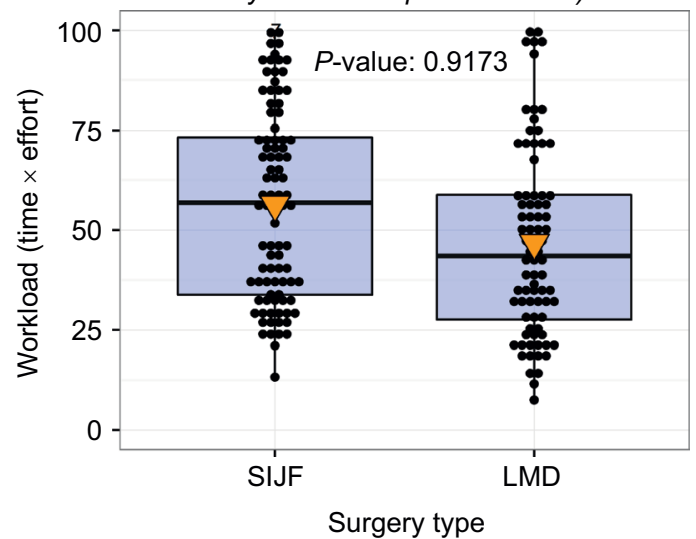

Workload: Physical

(How physically demanding was the task?)

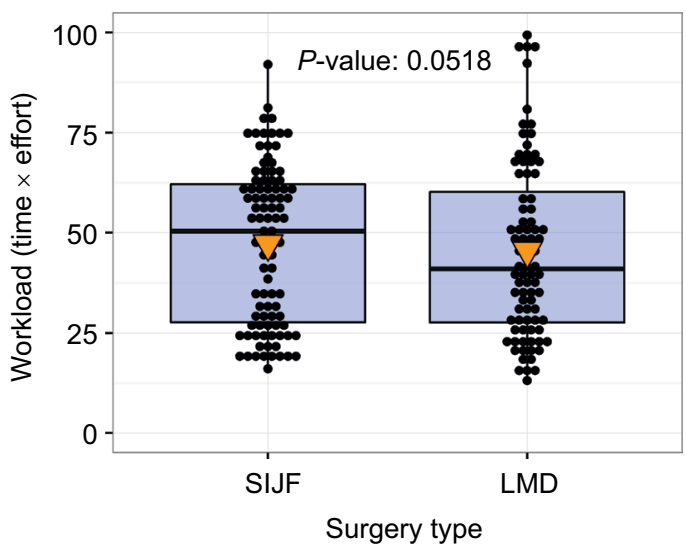

Workload: performance (How successful were you in accomplishing what you were asked to do?)

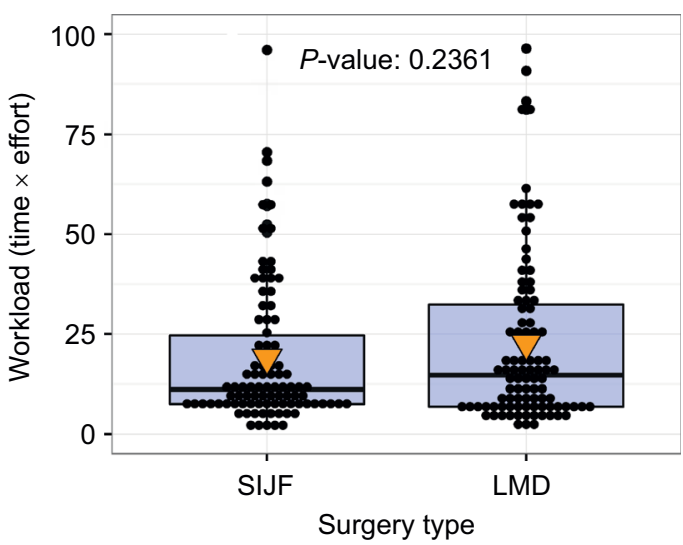

Workload: frustration (How insecure, discouraged, distressed did you feel?)

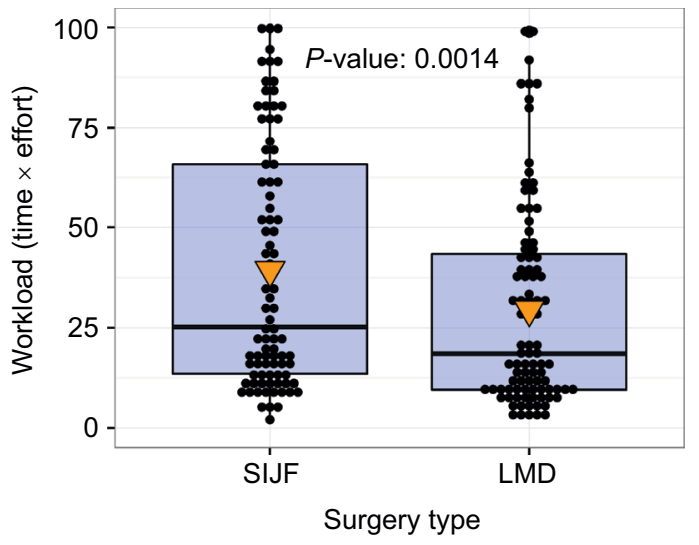

Figure 3 Workload by surgery type and subdomain.

Notes: Workload defined as TLX-rated intensity multiplied by OR time. P-values from mixed regression.

Abbreviations: OR, operating room; TLX, task load index; SIJF, sacroiliac joint fusion; LMD, lumbar microdiscectomy. 
underestimated and should be made at least commensurate with that of LMD.

The RVU approach aims to produce equitable reimbursement rates between procedure-based services and evaluation and management services. ${ }^{35}$ Inequitable fees could influence clinical decision-making by overvaluing some services and undervaluing others. The RVU approach incorporates three factors: total work input, an index of relative specialty practice costs, and the amortized value for the opportunity cost of specialized training. For the purposes of our analysis, the last two are not relevant as both procedures studied are performed by the same physician specialty type.

When the RVU approach was developed in the late 1980s, data for intraoperative service times were available, but no data were available to assess either intraoperative workload or pre- or postoperative service times. The RVU creators noted that due to the wide spectrum of procedures performed across all specialties, analyses focused on each procedure would be cost-prohibitive. Instead, physicians across a wide variety of specialties were asked to subjectively estimate workloads and data were obtained using nationwide surveys only. While the RVU process was historically private, it has now become more public, though methods to assess actual workload are still opaque. In contrast, our approach to estimating workload was substantially different, based on objective intraoperative data collected through the review of individual patient records by surgeons who actually performed the procedures. Moreover, our analysis took into account work intensity, as estimated based on surgeon assessments of individual cases using a standardized method (NASA TLX). For most measures, perceived work intensity was higher for SIJF vs LMD.

Our analysis has some limitations. Pre- and postoperative service times are not routinely collected. To address this, we estimated times through individual chart review. Similarly, intraoperative intensity is not captured routinely, and methods to measure intensity are varied and not universally accepted. We used an instrument often used to estimate task intensity (NASA-TLX) and calculated overall workload as time $\times$ intensity. This method has obvious advantages compared to the original RVU publication, ${ }^{53}$ which used survey data only. An additional limitation is the use of only five operative sites. However, the sites were disparate geographically. Moreover, our study involved surgeons of both orthopedic and neurosurgical background, increasing generalizability.

\section{Conclusion}

In summary, the RVU approach specifically aims to estimate overall workload by incorporating time and intensity of services delivered both during a procedure and in the pre- and postoperative time periods. ${ }^{35} \mathrm{~A}$ careful analysis of patients at five surgeon practices showed that preoperative, postoperative, and total labor times were higher for patients who underwent minimally invasive SIJF compared to LMD. Intensity measures were higher in most domains for SIJF, which offset somewhat lower procedure times. The RVU for minimally invasive SIJF should be adjusted upward.

\section{Disclosure}

Clay Frank, Dimitriy Kondrashov, S Craig Meyer, and Don Kovalsky conduct clinical research for SI-BONE. Dimitriy Kondrashov is a paid consultant to SI-BONE. Daniel Cher is an SI-BONE employee. SI-BONE manufactures the iFuse device, examined in this manuscript. The authors report no other conflict of interest in this work.

\section{References}

1. Salomon JA, Vos T, Hogan DR, et al. Common values in assessing health outcomes from disease and injury: disability weights measurement study for the Global Burden of Disease Study 2010. Lancet. 2012;380(9859): 2129-2143.

2. Rajaee SS, Bae HW, Kanim LE,Delamarter RB. Spinal fusion in the United States: analysis of trends from 1998 to 2008. Spine. 2012;37(1): 67-76.

3. Painter CF. Excision of the os innominatum. Arthrodesis of the sacro-iliac synchrondrosis. Boston Med Surg J. 1908;159:205-208.

4. Mixter W, Barr J. Rupture of the intervertebral disc with involvement of the spinal canal. N Engl J Med. 1934;211:210-215.

5. Sembrano JN, Polly DW Jr. How often is low back pain not coming from the back? Spine. 2009;34(1):E27-E32.

6. Bernard TN, Kirkaldy-Willis WH. Recognizing specific characteristics of nonspecific low back pain. Clin Orthop Relat Res. 1987;(217): 266-280.

7. Schwarzer AC, Aprill CN, Bogduk N. The sacroiliac joint in chronic low back pain. Spine. 1995;20(1):31-37.

8. Maigne JY, Aivaliklis A, Pfefer F. Results of sacroiliac joint double block and value of sacroiliac pain provocation tests in 54 patients with low back pain. Spine. 1996;21(16):1889-1892.

9. Liliang PC, Lu K, Liang CL, Tsai YD, Wang KW, Chen HJ. Sacroiliac joint pain after lumbar and lumbosacral fusion: findings using dual sacroiliac joint blocks. Pain Med. 2011;12(4):565-570.

10. DePalma MJ, Ketchum JM, Saullo TR. Etiology of chronic low back pain in patients having undergone lumbar fusion. Pain Med. 2011;12(5): 732-739.

11. Jackson R, Porter K. Current Concepts of Orthopaedic Physical Therapy; 2006.

12. Luukkainen R, Nissilä M, Asikainen E, et al. Periarticular corticosteroid treatment of the sacroiliac joint in patients with seronegative spondylarthropathy. Clin Exp Rheumatol. 1999;17(1):88-90.

13. Luukkainen RK, Wennerstrand PV, Kautiainen HH, Sanila MT, Asikainen EL. Efficacy of periarticular corticosteroid treatment of the sacroiliac joint in non-spondylarthropathic patients with chronic low back pain in the region of the sacroiliac joint. Clin Exp Rheumatol. 2002;20(1): $52-54$.

14. Cohen SP, Hurley RW, Buckenmaier CC 3rd, Kurihara C, Morlando B, Dragovich A. Randomized placebo-controlled study evaluating lateral branch radiofrequency denervation for sacroiliac joint pain. Anesthesiology. 2008;109(2):279-288.

15. Patel N, Gross A, Brown L, Gekht G. A randomized, placebo-controlled study to assess the efficacy of lateral branch neurotomy for chronic sacroiliac joint pain. Pain Med. 2012;13(3):383-398 . 
16. McGuire RA, Chen Z, Donahoe K. Dual fibular allograft dowel technique for sacroiliac joint arthrodesis. Evid Based Spine Care J. 2012;3(3): 21-28.

17. Kibsgård TJ, Røise $O$, Stuge B. Pelvic joint fusion in patients with severe pelvic girdle pain - a prospective single-subject research design study. BMC Musculoskelet Disord. 2014;15:85.

18. Schütz U, Grob D. Poor outcome following bilateral sacroiliac joint fusion for degenerative sacroiliac joint syndrome. Acta Orthop Belg. 2006;72(3):296-308.

19. Buchowski JM, Kebaish KM, Sinkov V, Cohen DB, Sieber AN, Kostuik JP. Functional and radiographic outcome of sacroiliac arthrodesis for the disorders of the sacroiliac joint. Spine J. 2005;5(5):520-528; discussion 529.

20. Belanger TA, Dall BE. Sacroiliac arthrodesis using a posterior midline fascial splitting approach and pedicle screw instrumentation: a new technique. J Spinal Disord. 2001;14(2):118-124.

21. Waisbrod H, Krainick JU, Gerbershagen HU. Sacroiliac joint arthrodesis for chronic lower back pain. Arch Orthop Trauma Surg. 1987;106(4): 238-240.

22. Moore MR. Surgical treatment of chronic painful sacroiliac joint dysfunction. In: Vlemming A, Mooney V, Snijders CJ, Stoeckart R, Livingstone C, editors. Movement, Stability, and Low Back Pain: The Essential Role of the Pelvis. Churchill Livingstone; 1997:563-572.

23. Lorio MP, Polly DW Jr, Ninkovic I, Ledonio CG, Hallas K, Andersson G. Utilization of minimally invasive surgical approach for sacroiliac joint fusion in surgeon population of ISASS and SMISS membership. Open Orthop J. 2014;8:1-6.

24. Polly DW, Cher DJ, Wine KD, et al. Randomized controlled trial of minimally invasive sacroiliac joint fusion using triangular titanium implants vs nonsurgical management for sacroiliac joint dysfunction: 12-month outcomes. Neurosurgery. 2015;77(5):674-690.

25. Duhon BS, Cher DJ, Wine KD, Kovalsky DA, Lockstadt H, SIFI Study Group. Triangular titanium implants for minimally invasive sacroiliac joint fusion: a prospective study. Global Spine J. 2016;6(3):257-269.

26. Rudolf L. Sacroiliac joint arthrodesis - MIS technique with titanium implants: report of the first 50 patients and outcomes. Open Orthop J. 2012;6:495-502.

27. Sachs D, Capobianco R. Minimally invasive sacroiliac joint fusion: one-year outcomes in 40 patients. Adv Orthop. 2013;2013:536128.

28. Cummings J Jr, Capobianco RA. Minimally invasive sacroiliac joint fusion: one-year outcomes in 18 patients. Ann Surg Innov Res. 2013;7(1):12.

29. Schroeder JE, Cunningham ME, Ross T, Boachie-Adjei O. Early results of sacro-iliac joint fixation following long fusion to the sacrum in adult spine deformity. HSS J. 2014;10(1):30-35.

30. Gaetani P, Miotti D, Risso A. Percutaneous arthrodesis of sacro-iliac joint: a pilot study. J Neurosurg Sci. 2013;57(4):297-301.

31. RudolfL, Capobianco R. Five-year clinical and radiographic outcomes after minimally invasive sacroiliac joint fusion using triangular implants. Open Orthop J. 2014;8:375-383.

32. Vanaclocha VV, Verdú-López F, Sánchez-Pardo M. Minimally invasive sacroiliac joint arthrodesis: experience in a prospective series with 24 patients. J Spine. 2014;3:5.

33. Graham Smith A, Capobianco R, Cher D. Open versus minimally invasive sacroiliac joint fusion: a multi-center comparison of perioperative measures and clinical outcomes. Ann Surg Innov Res. 2013;7(1):14.

34. Heiney J, Capobianco R, Cher D. A systematic review of minimally invasive sacroiliac joint fusion using a lateral transarticular approach. Int $J$ Spine Surg. 2015;9:40.
35. Hsiao WC, Braun P, Dunn D, BeckerER. Resource-based relative values:An overview. JAMA. 1988;260(16):2347-2353.

36. Chen P. How One Small Group Sets Doctors' Pay. Well (1316689213). Available from: http:/well.blogs.nytimes.com/2011/09/22/how-onesmall-group-sets-doctors-pay/. Accessed April 28, 2016.

37. CrowtherA. Inside Job. How an influential group of doctors exerts influence over medicare payments to physicians. AMA Medicare Self-Regulation Report. Washington: Public Citizen. Available from: http://www.citizen. org/public-citizen-inside-job-ama-self-regulation-medicare-report. Accessed April 28, 2016.

38. Hsiao WC, Braun P, Yntema D, Becker ER. Estimating physicians' work for a resource-based relative-value scale. N Engl J Med. 1988;319(13): $835-841$.

39. Garber T, Ledonio CG, Polly DW. How much work effort is involved in minimally invasive sacroiliac joint fusion? Int J Spine Surg. 2015;9:58.

40. Hart SG. Nasa-task load index (NASA-TLX); 20 years later. Proc Hum Factors Ergon Soc Annu Meet. 2006;50(9): 904-908.

41. R Development Core Team. R: A Language and Environment for Statistical Computing. Vienna, Austria:The R Foundation for Statistical Computing; 2013.

42. Sturesson B, Kools D, Pflugmacher R, et al. Six-month outcomes from a randomized controlled trial of minimally invasive SI joint fusion with triangular titanium implants vs conservative management. Eur Spine J. Epub 2016 May 14.

43. Duhon B, Bitan F, Lockstadt H, et al. Triangular titanium implants for minimally invasive sacroiliac joint fusion: 2-year follow-up from a prospective multicenter trial. Int J Spine Surg. 2016;10:13.

44. Rudolf L. MIS fusion of the SI joint: does prior lumbar spinal fusion affect patient outcomes? Open Orthop J. 2013;7:163-168.

45. Sachs D Capobianco R. One year successful outcomes for novel sacroiliac joint arthrodesis system. Ann Surg Innov Res. 2012;6(1):13.

46. Sachs D, Capobianco R, Cher D, et al. One-year outcomes after minimally invasive sacroiliac joint fusion with a series of triangular implants a multicenter, patient-level analysis. Med Devices. 2014;7:299-304.

47. Ledonio CG, Polly DW Jr, Swiontkowski MF. Minimally invasive versus open sacroiliac joint fusion: are they similarly safe and effective? Clin Orthop Relat Res. 2014;472(6):1831-1838.

48. Ledonio C, Polly DW Jr, Swiontkowski MF, Cummings JT Jr. Comparative effectiveness of open versus minimally invasive sacroiliac joint fusion. Med Devices. 2014;7:187-193.

49. Cher DJ, Frasco MA, Arnold RJ, Polly DW. Cost-effectiveness of minimally invasive sacroiliac joint fusion. Clinicoecon Outcomes Res. 2015;8: $1-14$.

50. Polly D, Cher D. Ignoring the sacroiliac joint in chronic low back pain is costly. Clinicoecon Outcomes Res. 2016;8:23-31.

51. Szadek KM, van der Wurff P, van Tulder MW, Zuurmond WW, Perez RS. Diagnostic validity of criteria for sacroiliac joint pain: a systematic review. J Pain. 2009;10(4):354-368.

52. Dunn D, Hsiao WC, Ketcham TR, Braun P.A method for estimating the preservice and postservice work of physicians' services. JAMA. 1988;260(16) 2371-2378.

53. Hsiao WC, Yntema DB, Braun P, Dunn D, Spencer C. Measurement and analysis of intraservice work. JAMA. 1988;260(16):2361-2370.

54. CMS.gov [homepage on the internet]. Medicare Physician Fee Schedule, Final Rule - Revisions to Payment Policies Under the Physician Fee Schedule and Other Revisions to Part B for CY 2016; Corrections. Addendum B. Available from: https:/www.cms.gov/Medicare/ Medicare-Fee-for-Service-Payment/PhysicianFeeSched/PFS-FederalRegulation-Notices-Items/CMS-1631-FC.html. Accessed April 12, 2016. 


\section{Publish your work in this journal}

ClinicoEconomics and Outcomes Research is an international, peerreviewed open-access journal focusing on health technology assessment, pharmacoeconomics and outcomes research in the areas of diagnosis, medical devices, and clinical, surgical and pharmacological intervention. The economic impact of health policy and health systems

organization also constitute important areas of coverage. The manuscript management system is completely online and includes a very quick and fair peer-review system, which is all easy to use. Visit http://www.dovepress.com/testimonials.php to read real quotes from published authors.

Submit your manuscript here: https://www.dovepress.com/clinicoeconomics-and-outcomes-research-journal 